\title{
Exendin-4 protects against post-myocardial infarction remodelling via specific actions on inflammation and the extracellular matrix
}

\author{
Emma Robinson $\cdot$ Roslyn S. Cassidy $\cdot$ Mitchel Tate $\cdot$ Youyou Zhao \\ Samuel Lockhart • Danielle Calderwood · Rachel Church • Mary K. McGahon · \\ Derek P. Brazil · Barbara J. McDermott · Brian D. Green · David J. Grieve
}

Received: 11 November 2014/Revised: 22 February 2015/Accepted: 23 February 2015/Published online: 1 March 2015

(C) The Author(s) 2015. This article is published with open access at Springerlink.com

\begin{abstract}
Glucagon-like peptide-1 (GLP-1) is an insulinreleasing hormone clinically exploited for glycaemic control in diabetes, which also confers acute cardioprotection and benefits in experimental/clinical heart failure. We specifically investigated the role of the GLP-1 mimetic, exendin-4, in post-myocardial infarction (MI) remodelling, which is a key contributor to heart failure. Adult female normoglycaemic mice underwent coronary artery ligation/ sham surgery prior to infusion with exendin-4/vehicle for 4 weeks. Metabolic parameters and infarct sizes were comparable between groups. Exendin- 4 protected against cardiac dysfunction and chamber dilatation post-MI and improved survival. Furthermore, exendin-4 modestly decreased cardiomyocyte hypertrophy/apoptosis but markedly attenuated interstitial fibrosis and myocardial inflammation post-MI. This was associated with altered extracellular matrix (procollagen I $\alpha \mathrm{I} / \mathrm{III} \alpha \mathrm{I}$, connective tissue growth factor, fibronectin, TGF- $\beta_{3}$ ) and inflammatory (IL-10, IL-1 $\beta$, IL-6) gene expression in exendin-4-treated
\end{abstract}

E. Robinson, R. S. Cassidy and M. Tate contributed equally to this work.

Electronic supplementary material The online version of this article (doi:10.1007/s00395-015-0476-7) contains supplementary material, which is available to authorized users.

E. Robinson - R. S. Cassidy - M. Tate - Y. Zhao - S. Lockhart ·

R. Church · M. K. McGahon - D. P. Brazil ·

B. J. McDermott · D. J. Grieve $(\bowtie)$

Centre for Experimental Medicine, Institute of Clinical Science

Block A, Queen's University Belfast, Grosvenor Road,

Belfast BT12 6BA, UK

e-mail: d.grieve@qub.ac.uk

D. Calderwood - B. D. Green

School of Biological Sciences, Queen's University Belfast, Belfast BT9 5AG, UK mice, together with modulation of both Akt/GSK-3 $\beta$ and Smad2/3 signalling. Exendin-4 also altered macrophage response gene expression in the absence of direct actions on cardiac fibroblast differentiation, suggesting cardioprotective effects occurring secondary to modulation of inflammation. Our findings indicate that exendin-4 protects against post-MI remodelling via preferential actions on inflammation and the extracellular matrix independently of its established actions on glycaemic control, thereby suggesting that selective targeting of GLP-1 signalling may be required to realise its clear therapeutic potential for postMI heart failure.

Keywords Glucagon-like peptide-1 $\cdot$ Myocardial infarction - Cardiac remodelling - Extracellular matrix . Inflammation

\section{Introduction}

Chronic heart failure (CHF) affects up to $2 \%$ of the adult population in the western world and carries a poor prognosis, with the underlying aetiology shifting towards ischaemia [1, 2]. Acute remodelling in the infarct zone occurs within the first few days after myocardial infarction (MI) and involves apoptosis and inflammation which drive scar formation, whereas post-MI remodelling affecting the remote viable myocardium includes initial adaptive changes in cardiomyocyte biology and the extracellular matrix (ECM) progressing to maladaptive left ventricular (LV) dilatation, chronic myocardial inflammation, cardiomyocyte hypertrophy/apoptosis and interstitial fibrosis, which contribute to associated contractile dysfunction and ultimately CHF [3]. Despite optimal pharmacological and surgical management of post-MI patients there remains a 
substantial incidence of CHF $[4,5]$, so the need for more effective therapeutic strategies is clear.

In this regard, the incretin hormone, glucagon-like peptide-1 (GLP-1), is emerging as a potential candidate. Beyond its established role in glycaemic control, accumulating evidence supports other important physiological roles for GLP1 , particularly in the cardiovascular system $[6,7]$, where the GLP-1 receptor (GLP-1R) is widely expressed and mediates key functions including heart rate/contractility, cardiac structure/contractility, blood pressure and vascular tone [812]. Importantly, GLP-1 also confers beneficial actions on cardiovascular disease, both experimental and clinically, in the presence or absence of diabetes [13-18].

The majority of studies investigating cardiac effects of GLP-1 have focused on its actions in ischaemia and ability to protect cardiomyocytes from acute damage. For example, it is well established that GLP-1R agonists and dipeptidyl peptidase-4 (DPP-4) inhibitors, which increase endogenous GLP-1, reduce infarct size after experimental ischaemia and enhance functional recovery upon reperfusion $[8,19,20]$. Furthermore, the GLP-1R agonist, liraglutide, increases survival in experimental MI, and cardiac function after ischaemia-reperfusion injury is improved in DPP-4 ${ }^{-/-}$mice $[15,17]$. GLP-1 also protects against LV dysfunction in experimental models of dilated cardiomyopathy, hypertensive CHF and MI, at least partly by increasing myocardial glucose uptake [14, 16, 21]. Importantly these benefits appear to translate to the clinical setting with GLP-1 improving cardiac function in CHF and in MI patients after primary angioplasty [18, 22].

Although the acute cardioprotective actions of GLP-1 are well established, little attention has previously been paid to specific effects on post-MI remodelling, which is a major contributor to CHF progression [3]. However, two studies have now reported beneficial actions of the GLP-1 analogues, AC3174 and exendin-4, on post-MI survival and cardiac structure/function in rodent models, when administered from 2 days and 2 weeks after coronary artery ligation, respectively [21, 23], although another study failed to demonstrate equivalent beneficial effects when liraglutide was given 7 days post-MI [24]. As previous work suggests that GLP-1 modulates several signalling pathways related to specific facets of post-MI remodelling, including cardiomyocyte apoptosis, fibrosis and inflammation [25-30], which are key determinants of CHF progression, a more detailed focus on individual remodelling components was considered to be crucial. The aim of this study was therefore to precisely define the apparently favourable actions of the peptide in this setting, testing the hypothesis that exendin-4 attenuates post-MI remodelling via differential modulation of distinct aspects of the remodelling phenotype. Importantly, we report for the first time specific beneficial actions of exendin-4 on post-MI remodelling, which appear to involve preferential targeting of the ECM secondary to modulation of myocardial inflammation.

\section{Methods}

Experimental model

Female C57BL/6J mice (8-12 weeks; Harlan UK) were used throughout this study and were housed under constant climatic conditions with free access to food and water. All experimental procedures were performed in accordance with the Guidance on the Operation of the Animals (Scientific Procedures) Act, 1986 (UK) and approved by the Queen's University Belfast Animal Welfare and Ethical Review Body. Experimental animals were randomised (by drawing of lots) and subjected to permanent ligation of the left anterior descending coronary artery under $2 \%$ isoflurane/ oxygen anaesthesia, or sham surgery which involved an identical procedure with the exception of coronary artery ligation, and subsequent analyses performed at 4 weeks. Buprenorphine analgesia $(0.05 \mathrm{mg} / \mathrm{kg}$ i.m.) was administered prior to and after surgery, as required. Female mice were used as previous studies have shown them to carry significantly lower peri-operative mortality versus males [31]. To investigate the effects of GLP-1 on post-MI remodelling, MI or sham-operated mice were randomly assigned to be chronically infused with either the DPP-4 resistant GLP-1 mimetic, exendin-4 (at a concentration employed in previous studies relating to the anti-diabetic and cardioprotective actions of GLP-1; $25 \mathrm{nmol} / \mathrm{kg} / \mathrm{day}$; GL Biochem, average purity $90 \%)[12,15,16,32]$, or saline control via an osmotic minipump (Alzet model 1004) implanted immediately after MI surgery. For ex vivo analysis of infarct size and gene/protein expression, animals were killed by sodium pentobarbitone overdose before hearts were excised and either perfused with Evan's blue dye or non-infarcted tissue frozen in liquid nitrogen and stored at $-80{ }^{\circ} \mathrm{C}$ for further studies. For analysis of post-MI remodelling, hearts were arrested in diastole by injection of $10 \%$ $\mathrm{KCl}$, fixed in $10 \%$ neutral-buffered formalin solution, paraffin-embedded and sectioned. A minimum of five animals per group were studied for all protocols.

Assessment of plasma glucose, insulin and lipids

Terminal blood samples were collected by cardiac puncture into heparinised tubes and centrifuged at $10,000 \mathrm{~g}$ for 10 min to obtain plasma fractions. Plasma samples were analysed using enzymatic assay kits (Analox Ltd) for glucose (GMRD-002A using glucose oxidase), cholesterol (GMRD-084 using cholesterol esterase) and triglyceride (GMRD-195 using lipase) detected on a GM7 Micro-Stat 
Analyser (Analox Instruments Ltd). Plasma insulin concentrations were assayed using an ELISA kit (ALPCO Diagnostics), measuring absorbance at $450 \mathrm{~nm}$ on a microplate reader (Tecan Safire). Plasma glycated haemoglobin, HbA1c, was assessed using a commercially available assay kit (Helena Laboratories), measuring absorbance at $415 \mathrm{~nm}$ on a microplate reader (Tecan Safire) and expressed as percentage of total haemoglobin.

Plasma adipokine expression

Adipokine protein expression was assessed in six pooled plasma samples from each experimental group using a Proteome Profiler ${ }^{\mathrm{TM}}$ antibody array (R\&D Systems).

\section{Infarct size}

Excised hearts were initially perfused retrogradely with Evans blue dye (1\% in saline) to determine area at risk. Hearts were then sliced into five serial transverse sections $(1 \mathrm{~mm})$ and incubated in $1 \%$ triphenyltetrazolium chloride at $37{ }^{\circ} \mathrm{C}$ to identify infarcted myocardium. Infarct area, area at risk and total LV area from each section were measured using computerised planimetry (ImageJ), and totalled for all sections. Infarct size was expressed as a percentage of area at risk.

Echocardiography and invasive assessment of cardiac function

Mice were anaesthetised with $1.5 \%$ isoflurane/oxygen, placed on a warming pad, and imaged in the supine position using a Vevo770 ultrasound system with high-frequency $45 \mathrm{MHz}$ RMV707B scanhead (VisualSonics, Inc.). M-mode parasternal short-axis scans at papillary muscle level were used to quantify LV end-diastolic (LVEDD) and end-systolic diameters (LVESD) from which \% fractional shortening was calculated (LVEDD - LVESD)/ LVEDD $\times 100$. Parasternal long-axis scans were used to provide additional data on LV end-diastolic (LVEDV) and end-systolic volumes (LVESV) and ejection fraction and pulse-wave Doppler was used to assess mitral valve flow (E/A ratio) as a measure of diastolic function. Isoflurane was then increased to $2 \%$ before the right carotid artery was cannulated with a high-fidelity $1.2 \mathrm{~F}$ pressure catheter (FTS-1211B-0018; Scisense Inc.), aortic pressure measured, and the catheter advanced into the LV for recording of steady-state function.

Assessment of post-MI remodelling

Following killing, hearts were weighed and measurements normalised to total body weight. All histological analyses were performed on fixed (10\% neutral-buffered formalin), paraffin-embedded $\mathrm{LV}$ sections $(5 \mu \mathrm{m})$. Cardiomyocyte cross-sectional area was determined by H\&E staining, analysing cells with centrally located nuclei. Cardiac interstitial fibrosis was assessed by picrosirius red staining $(0.1 \% \mathrm{w} / \mathrm{v})$, excluding coronary vessels and perivascular regions. Data were quantified by digital image analysis (NIS-Elements, Nikon) with the observer blinded to sample identity.

Immunohistochemistry for CD45 and F4/80 was performed with rabbit polyclonal (Millipore), rat polyclonal (BD Biosciences), and rat monoclonal (Abcam) antibodies (1:1000), respectively, using diaminobenzidine as the chromogen and nuclear counterstaining with haematoxylin. Data were quantified by blinded digital image analysis (NIS-Elements).

Cardiomyocyte apoptosis was determined by terminal deoxynucleotidyl transferase-mediated dUTP nick end labelling (TUNEL) staining (Roche Diagnostics). TUNELpositive cardiomyocyte nuclei were counted, and data expressed as $\%$ total nuclei identified by $4^{\prime}, 6$-diamidino-2phenylindole staining in the same sections.

In vitro cardiomyocyte remodelling studies

To investigate direct effects of exendin- 4 on cardiomyocyte remodelling, a series of studies were conducted in rat ventricular $\mathrm{H} 9 \mathrm{c} 2$ cardiomyoblasts and mouse atrial HL-1 cardiomyocytes, to assess actions on cell hypertrophy and apoptosis, respectively. H9c2 cardiomyoblasts were maintained in DMEM containing $10 \% \mathrm{FCS}, 100 \mathrm{U} / \mathrm{ml}$ penicillin and $100 \mu \mathrm{g} / \mathrm{ml}$ streptomycin. At passage, they were plated, cultured to $\sim 50 \%$ confluency and serum-starved for $24 \mathrm{~h}$ prior to incubation with phenylephrine $(1 \mu \mathrm{mol} / \mathrm{L}$ for $96 \mathrm{~h})$ to induce hypertrophy in the presence or absence of exendin$4(0.1 \mu \mathrm{mol} / \mathrm{L})$ [33]. H9c2 cardiomyoblast cross-sectional area was quantified by blinded digital image analysis (NISElements) as an index of cell hypertrophy. HL-1 cells were maintained in Claycomb media containing $10 \%$ FCS, $0.1 \mathrm{mmol} / \mathrm{L}$ norepinephrine, $2 \mathrm{mmol} / \mathrm{L}$ L-glutamate, $100 \mathrm{U} /$ $\mathrm{ml}$ penicillin and $100 \mu \mathrm{g} / \mathrm{ml}$ streptomycin. At passage, they were plated and cultured to sub-confluency (70-80 \%) prior to incubation with doxorubicin $(5 \mu \mathrm{mol} / \mathrm{L}$ for $24 \mathrm{~h})$ to induce apoptosis in the presence or absence of exendin- 4 $(0.1 \mu \mathrm{mol} / \mathrm{L})$ [34]. Caspase $3 / 7$ activity (Caspase-Glo ${ }^{\circledR}$, Promega UK) was quantified as a measure of apoptosis and data normalised to cell viability assessed by CellTiter-Blue ${ }^{\circledR}$ assay (Promega, UK).

Real-time reverse transcription-PCR

Total RNA was extracted from LV homogenate using TRI reagent (Sigma-Aldrich), and cDNA synthesised by reverse 
transcription (Applied Biosystems). mRNA expression of atrial natriuretic peptide (ANP), procollagen I $\alpha$ I, procollagen III $\alpha$ I, connective tissue growth factor (CTGF), fibronectin, TGF- $\beta_{3}$, IL-10, IL-1 $\beta$, IL- 6 and GLP-1R was analysed by real-time reverse transcription-PCR (RT-PCR) using fluorescent SYBR Green (Prism 7300, Applied Biosystems) and $\beta$-actin for normalisation by the comparative $C_{\mathrm{t}}$ method. Primer sequences are shown in Online Resource 1.

\section{Western blotting}

LV protein was extracted by homogenisation with ice-cold RIPA buffer, as previously described [31], and $20 \mu \mathrm{g}$ loaded onto a $10 \%$ SDS-PAGE gel before blotting on a polyvinylidene fluoride membrane (Immobilon-FL; Millipore). Membranes were probed overnight at $4{ }^{\circ} \mathrm{C}$ with rabbit monoclonal antibodies $(1: 1000)$ against total glycogen synthase kinase $3 \beta$ (GSK3 $\beta$; Cell Signaling Technology), phospho-GSK3 $\beta$ (Ser9; Cell Signaling Technology) and discoidin domain receptor 2 (DDR2; Abcam), and rabbit polyclonal antibodies (1:1000) against total Akt, phospho-Akt (Ser473), Smad2/3 (both from Cell Signaling Technology) and phospho-Smad2/3 (Ser423/ 425; Santa Cruz Biotechnology), using rabbit polyclonal HPRT2 antibody (Abcam; 1:1000) as a loading control. This was followed by incubation with peroxidase-labelled goat anti-rabbit secondary antibody (Cell Signaling Technology; 1:10,000) for $60 \mathrm{~min}$ at room temperature, before the membrane was developed in a darkroom using ECL reagent (Millipore), scanned and quantified by densitometry (ImageJ).

Murine cardiac fibroblast isolation and culture

Murine cardiac fibroblasts were isolated from male C57BL/6J mice based on a previously published method [35]. Mice (5 per isolation) were euthanised with sodium pentobarbitone (200 mg/kg i.p.) and heparin (100 IU/100 g i.p.) and their hearts removed immediately into ice-cold Krebs-Henseleit buffer (KHB). After rinsing twice in $\mathrm{KHB}$, ventricles were isolated, finely minced in KHB and mixed vigorously with $4 \mathrm{ml}$ Liberase $^{\mathrm{TM}}$ solution (Roche, Sussex, UK) at $37^{\circ} \mathrm{C}$ for $8 \mathrm{~min}$. The supernatant was then removed and added to $10 \mathrm{ml}$ ice-cold KHB to inhibit enzyme activity, whilst $3 \mathrm{ml}$ Liberase $^{\mathrm{TM}}$ was added to the undigested tissue and the process repeated a 3 further times. The combined supernatant was filtered and centrifuged at $200 \mathrm{~g}$ for $5 \mathrm{~min}$ and the resultant pellet resuspended in DMEM supplemented with $10 \%$ FBS, $20 \mathrm{mmol} / \mathrm{L} \mathrm{L}$-glutamine, $100 \mathrm{U} / \mathrm{ml}$ penicillin and $100 \mathrm{mg} /$ $\mathrm{ml}$ streptomycin, and transferred to a $1 \%$ gelatin-coated T75 flask with $10 \mathrm{ml}$ DMEM at $37{ }^{\circ} \mathrm{C}$ in a humidified atmosphere of $5 \% \mathrm{CO}_{2}$. After $2 \mathrm{~h}$, non-adherent cells were removed and the remaining primary cardiac fibroblasts cultured for approximately 7 days until $90 \%$ confluent. Cells were then washed with PBS, detached with $0.25 \%$ trypsin and centrifuged in DMEM at $200 \mathrm{~g}$ for $5 \mathrm{~min}$. The cell pellet was suspended in fresh DMEM and fibroblasts seeded at 1:2 for expansion before being used for experiments at passage 2 . Fibroblasts were treated with or without TGF- $\beta$ ( $5 \mathrm{ng} / \mathrm{ml})$, to induce myofibroblast differentiation, in the presence or absence of exendin-4 (10 n$\mathrm{mol} / \mathrm{L}$ ) for $24 \mathrm{~h}$ prior to assessment of gene expression. Protein was prepared as described previously, and probed for $\alpha$-smooth muscle actin using a mouse monoclonal antibody (Dako; 1:2000) and mouse monoclonal $\beta$-actin antibody (Cell Signaling Technology; 1:50,000) as a loading control. This was followed by incubation with Alexa Fluor $^{\circledR} 594$ goat anti-mouse (Molecular Probes; 1:10,000) and horse anti-mouse (Cell Signaling Technology; $1: 10,000)$ secondary antibodies, respectively, for $60 \mathrm{~min}$ at room temperature, before membranes were developed in a darkroom using ECL reagent (Millipore), scanned and quantified by densitometry (ImageJ). The same $\alpha$-smooth muscle actin antibody was used at 1:200 to visualise actin myofilament differentiation with DAPI nuclear counterstaining imaged on a fluorescence microscope at 200x magnification (Nikon Eclipse). RNA/cDNA was also prepared as described previously, and CTGF mRNA expression assessed by real-time RT-PCR using fluorescent SYBR Green and GAPDH for normalisation. Primer sequences are shown in Online Resource 1.

Murine bone marrow-derived macrophage isolation and culture

Murine bone marrow-derived macrophages were isolated from male C57BL/6J mice, as previously described [36]. Mice were euthanised with sodium pentobarbitone $(200 \mathrm{mg} / \mathrm{kg}$ i.p.) and their femurs isolated and rinsed in DMEM supplemented with $10 \%$ FBS and $100 \mathrm{U} / \mathrm{ml}$ penicillin and $100 \mathrm{mg} / \mathrm{ml}$ streptomycin. Bone marrow cells were then flushed out with fresh DMEM using a 23-gauge needle and centrifuged at $500 \mathrm{~g}$ for $10 \mathrm{~min}$ at $4{ }^{\circ} \mathrm{C}$. Media was aspirated and cells were resuspended in ACK lysis buffer at room temperature for $3 \mathrm{~min}$ to destroy any contaminating red blood cells. The lysate was then quenched with excess DMEM and centrifuged as before. Bone marrow cells were then resuspended in DMEM supplemented with L929 cell supernatant (1:6) containing macrophage colony-stimulating factor to induce differentiation, and seeded into a $150 \mathrm{~mm}$ tissue culture plate. At day 2, media was replaced with fresh DMEM supplemented with L929 supernatant to remove any non-adherent 
cells. At day 4, cells were washed and scraped into DMEM prior to centrifugation at $500 \mathrm{~g}$ for $10 \mathrm{~min}$ at $4{ }^{\circ} \mathrm{C}$, and seeded 1:3 into tissue culture plates containing DMEM supplemented with L929 supernatant. At day 8, cells were counted and split into 6-well plates, each containing 1 million cells, prior to incubation for a further $24 \mathrm{~h}$ in DMEM without L929 supernatant in the presence or absence of exendin-4 (1 nmol/L). RNA/ cDNA and protein were then prepared for gene expression analysis, as described previously. mRNA expression of CD11b, IL-10, MMP-9, FGF-2, IL-1 $\beta$ and CCL2 was analysed by real-time RT-PCR using fluorescent SYBR Green and GAPDH for normalisation. Primer sequences are shown in Online Resource 1. Secreted cytokine expression was assessed in pooled conditioned media from each experimental group using a Proteome Profiler ${ }^{\mathrm{TM}}$ antibody array (R\&D Systems). Immunocytochemistry for GLP-1R was performed in both BMDM and cardiac fibroblasts using a rabbit polyclonal antibody (Abcam: 1:200) with DAPI nuclear counterstaining, whilst GLP-1R protein expression was quantified in BMDM by Western blot using the same primary antibody $(1: 1000)$ and a mouse monoclonal $\beta$ actin antibody (Cell Signaling Technology: 1:50,000) as the loading control.

\section{Statistics}

Data are expressed as mean \pm SEM and were analysed by either an unpaired $t$ test, one-way ANOVA followed by a Bonferroni or Dunnett's multiple comparison test, or Kaplan-Meier survival analysis using a log-rank test. $P<0.05$ was considered to be statistically significant.

\section{Results}

Metabolic data

Metabolic parameters are summarised in Table 1. Body weight was not different between groups. Similarly, chronic infusion with exendin-4 for 4 weeks had no effect on plasma glucose, HbA1c, insulin, cholesterol or triglyceride concentrations, whilst minimal differences in plasma adipokine expression were observed (Online Resource 2).

\section{Infarct size}

Area at risk was similar between MI groups (control: $73.6 \pm 2.0$, exendin-4: $72.4 \pm 2.3 \% \mathrm{LV} ; n \geq 11$ ) after 4 weeks. Infarct sizes were also comparable between MI groups (control: $57.9 \pm 4.2$, exendin-4: $59.2 \pm 4.3 \%$ area at risk; $n \geq 11$ ). However, survival rate at 4 weeks post-MI tended to be higher after exendin-4 treatment (MI control: $67.6 \%, n=68 ; \quad$ MI exendin-4: $80.3 \%, \quad n=76$; $P=0.07)$. Only one death was observed in the sham groups $(n=58)$.

\section{Cardiac function}

Echocardiography data are presented in Fig. 1a-d. LV dilatation in response to MI, as measured by LVEDV, was reduced by exendin-4. Similarly, exendin-4-treated mice demonstrated improved systolic function post-MI, reflected by higher ejection fraction and lower LVESV. Furthermore, diastolic dysfunction, indicated by a reduced mitral valve $E / A$ ratio in $\mathrm{MI}$ controls, was not evident after exendin-4 treatment. Similar functional changes were observed after assessment of LV dimension-derived parameters (LVEDD, LVESD, fractional shortening) and these data are presented in Online Resource 3. Heart rate remained similar between groups.

Cardiac catheterisation data are summarised in Fig. 1eh. Post-MI decreases in systolic function, measured by $\mathrm{LVd} P / \mathrm{d} t_{\max }$, were attenuated by exendin-4. Similarly, exendin-4-treated mice demonstrated better preserved LV relaxation after $\mathrm{MI}$, indexed by $\mathrm{LVd} P / \mathrm{d} t_{\min }$ and the isovolumetric relaxation time constant, $\tau$, and a tendency towards improved diastolic function, reflected by reduced LV end-diastolic pressure. Mean arterial blood pressure (control: $64.2 \pm 0.9$, exendin-4: $67.4 \pm 1.2$, MI control: $64 \pm 2.7, \quad 66.0 \pm 1.6 \mathrm{mmHg} ; n=9-15, \quad P=\mathrm{NS})$ and

Table 1 Effect of exendin-4 on metabolic parameters

\begin{tabular}{lllll}
\hline & Sham control & MI control & Sham exendin-4 & MI exendin-4 \\
\hline Body weight $(\mathrm{g}) n=19$ & $22.9 \pm 0.4$ & $23.7 \pm 0.5$ & $23.0 \pm 0.3$ & $23.2 \pm 0.3$ \\
Plasma glucose (mmol/L) $n=7-12$ & $13.6 \pm 1.8$ & $12.6 \pm 0.7$ & $13.1 \pm 1.0$ & $13.9 \pm 0.9$ \\
Plasma HbA1c $(\%) n=4-6$ & $6.81 \pm 0.23$ & $6.90 \pm 0.43$ & $6.32 \pm 0.32$ & $6.08 \pm 0.22$ \\
Plasma insulin (mmol/L) $n=10-12$ & $0.56 \pm 0.06$ & $0.47 \pm 0.04$ & $0.53 \pm 0.07$ & $0.64 \pm 0.11$ \\
Plasma cholesterol (mmol/L) $n=10-12$ & $1.71 \pm 0.07$ & $1.88 \pm 0.08$ & $1.85 \pm 0.09$ & $1.84 \pm 0.10$ \\
Plasma triglyceride (mmol/L) $n=10-11$ & $1.32 \pm 0.11$ & $1.24 \pm 0.14$ & $0.90 \pm 0.09$ & $1.25 \pm 0.11$ \\
\hline
\end{tabular}

Mean \pm SEM. $P=$ NS 


\section{Echocardiography}
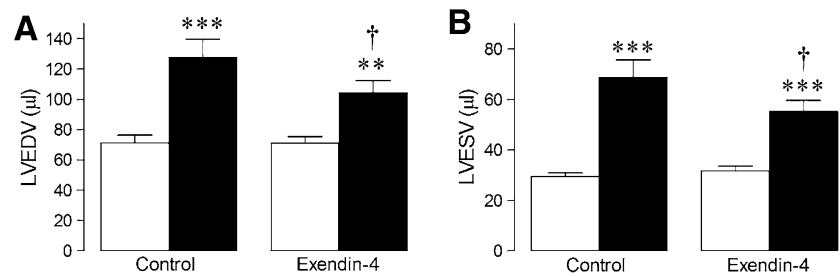

Cardiac catheterisation

E
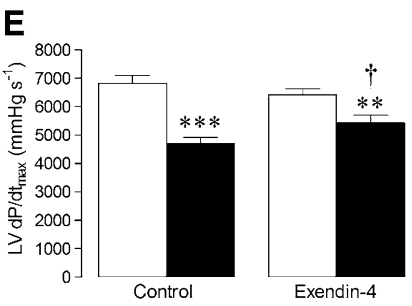

$\mathbf{F}$
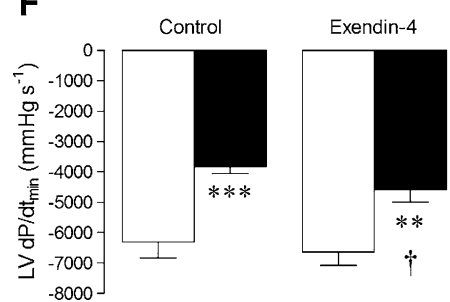

Fig. 1 Effect of exendin-4 on cardiac function post-MI. a LV enddiastolic volume (LVEDV), b LV end-systolic volume (LVESV), c $\mathrm{LV}$ ejection fraction, d mitral valve (MV) $E / A$ ratio, assessed by echocardiography $(n=10-16)$. e LV $\mathrm{d} P / \mathrm{d} t_{\max } ; \mathbf{f ~ L V ~} \mathrm{d} P / \mathrm{d} t_{\min } ; \mathbf{g} \tau$; h LV end-diastolic pressure (LVEDP), assessed by cardiac

heart rate (control: $484 \pm 24$, exendin-4: $486 \pm 16$, MI control: $478 \pm 14,472 \pm 13 \mathrm{bpm} ; n=9-15, P=\mathrm{NS})$ remained similar between groups.

\section{Cardiomyocyte remodelling}

Chronic exendin-4 treatment reduced MI-induced myocardial hypertrophy, as indicated by heart/body weight ratio and cardiomyocyte area (Fig. 2a, b), although it had no effect on mRNA expression of ANP (Fig. 2c), an established marker of hypertrophy. Similarly, in vitro phenylephrine-induced hypertrophy of H9c2 cardiomyoblasts was attenuated by exendin-4 (Fig. 2d). MI-induced cardiomyocyte apoptosis, assessed in LV sections by TUNEL staining, was also decreased by exendin-4 (Fig. 2e), although acute treatment had no significant effect on in vitro doxorubicin-induced apoptosis in HL-1 cardiomyocytes (Fig. 2f).

\section{Extracellular matrix remodelling}

Interstitial fibrosis was markedly decreased in exendin-4treated MI mice compared to MI controls (Fig. 3a-e). Consistent with this, MI-induced increases in mRNA expression of several key ECM genes, procollagen I $\alpha$ I, procollagen III $\alpha$ I, CTGF, fibronectin and TGF- $\beta_{3}$, were reduced by exendin-4 (Fig. $3 \mathrm{f}-\mathrm{j}$ ). In addition, protein expression of the fibroblast marker, DDR2, was increased in MI exendin-4-treated mice compared to MI controls (Fig. 3k) [37, 38].
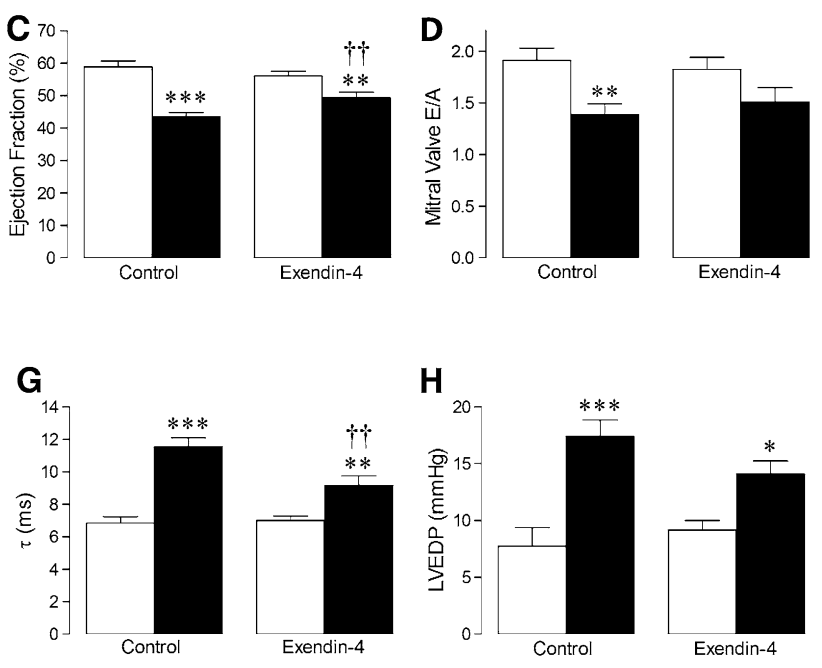

catheterisation ( $n=9-15)$. White columns sham, black columns $\mathrm{MI}$, mean \pm SEM. ${ }^{*} P<0.05$, $* * P<0.01$, $* * * P<0.001$, versus corresponding sham; ${ }^{\dagger} P<0.05,{ }^{\dagger} P<0.01$, MI exendin-4 versus MI control

Myocardial inflammation

Myocardial infiltration of CD45-positive leukocytes and F4/80-positive macrophages after MI was completely prevented by exendin-4 (Fig. 4a-k). Consistent with this, MIinduced alterations in mRNA expression of the inflammatory cytokines, IL-10, IL-1 $\beta$ and IL- 6 , were normalised by exendin-4 (Online Resource 4).

\section{GLP-1R receptor expression}

GLP-1R mRNA expression was increased in MI controls and attenuated by exendin-4 (Online Resource 5).

Investigation of potential cardioprotective signalling mechanisms

Several candidate pathways which may mediate the protective effects of exendin-4 on post-MI remodelling were investigated. Phosphorylation of the pro-survival kinase Akt was clearly elevated by exendin-4 after MI, in association with an apparent increase in total protein expression (Fig. 5a-c). Furthermore, both total and phosphorylated GSK-3 $\beta$, a known substrate of Akt, which has been proposed as a convergence point for several cardioprotective pathways and specifically suppresses cardiac fibroblastdriven remodelling [39, 40], was markedly increased by exendin-4 (Fig. 5d-f), indicating deactivation of GSK-3 $\beta$ signalling. In addition, the expression and activity of two key Smad proteins, which are important regulators of TGF- 
A
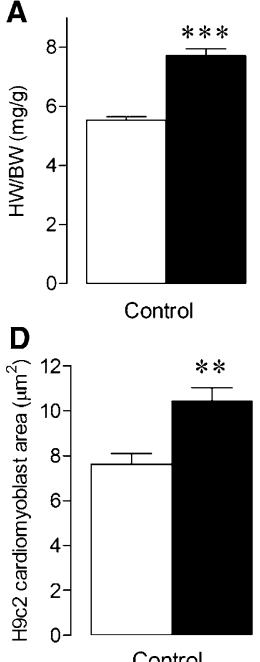

Control
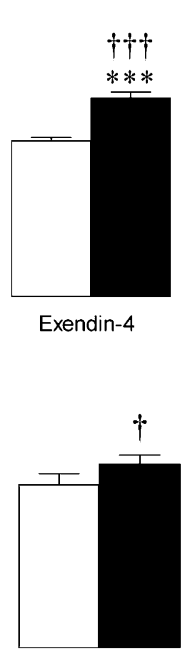

Exendin-4

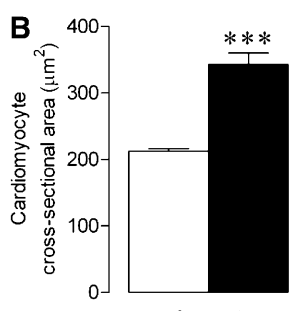

Control

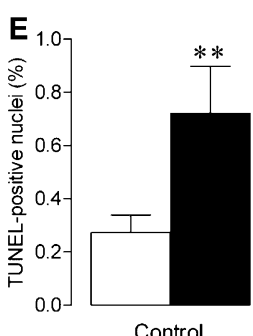

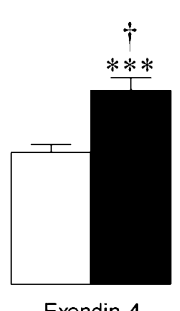

Exendin-4

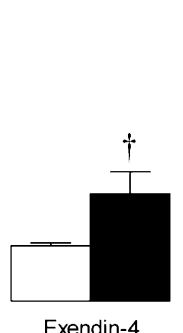

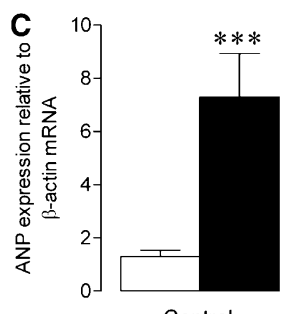

Control

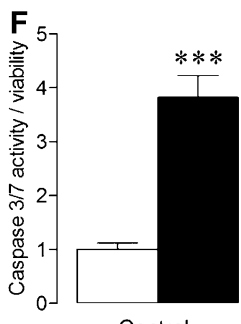

Control
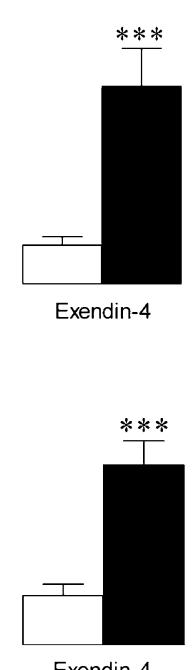

Fig. 2 Effect of exendin-4 on cardiomyocyte remodelling after MI. a Heart weight/body weight (HW/BW; $n=24-29)$, b cardiomyocyte cross-sectional area $(n=6)$, c ANP mRNA expression $(n=6-8)$, d phenylephrine-induced $\mathrm{H} 9 \mathrm{c} 2$ cardiomyoblast hypertrophy ( $n=7-8)$, e TUNEL staining $(n=6)$, f doxorubicin-induced HL-1 cardiomyocyte apoptosis $(n=6)$. White columns sham $(\mathbf{a}-\mathbf{c}, \mathbf{e})$ or untreated cells (d, f); black columns MI (a-c, e) or phenylephrine/doxorubicin-treated cells $(\mathbf{d}, \mathbf{f}) ;$ mean \pm SEM. $* * P<0.01$, $* * * P<0.001$, versus corresponding sham/untreated control; ${ }^{\dagger} P<0.05,{ }^{\dagger \dagger} P<0.001$, MI exendin-4 versus MI control or phenylephrine exendin-4 versus phenylephrine control

\section{A Sham control}

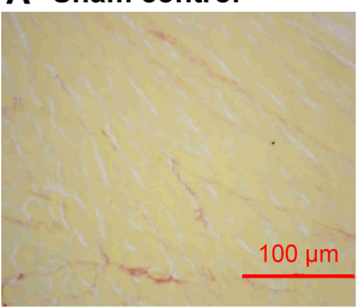

C Sham exendin-4
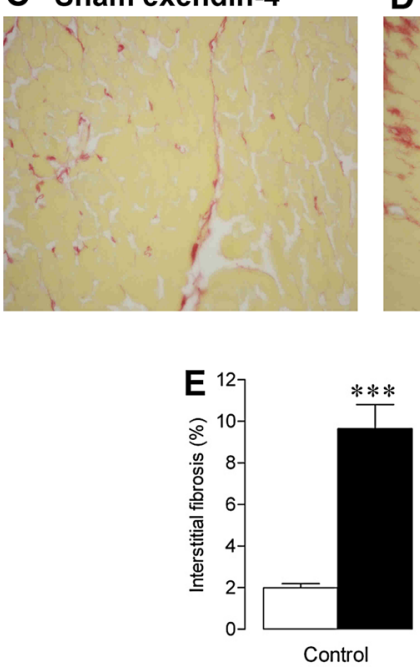

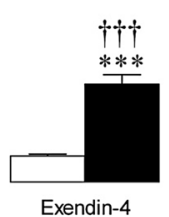

\section{B MI control}

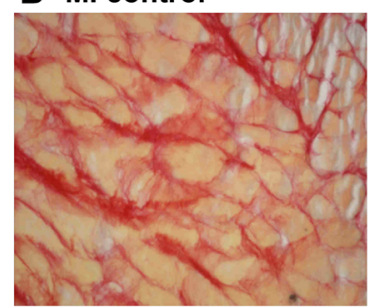

\section{MI exendin-4}

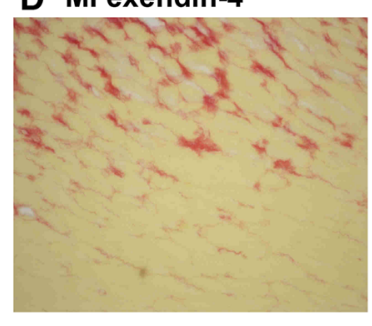

Exendin-4

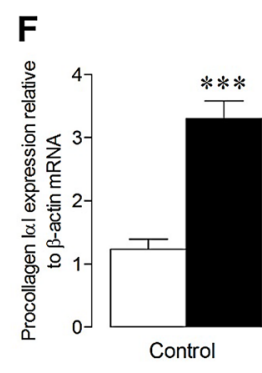

H
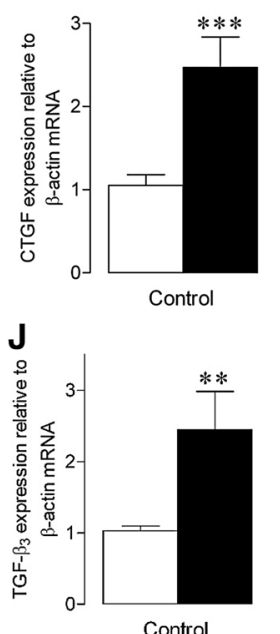

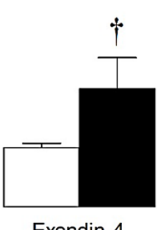

Exendin-4

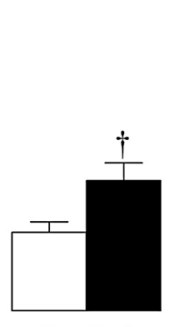

Exendin-4

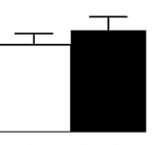

Exendin-4

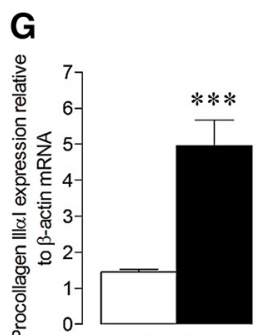

Control
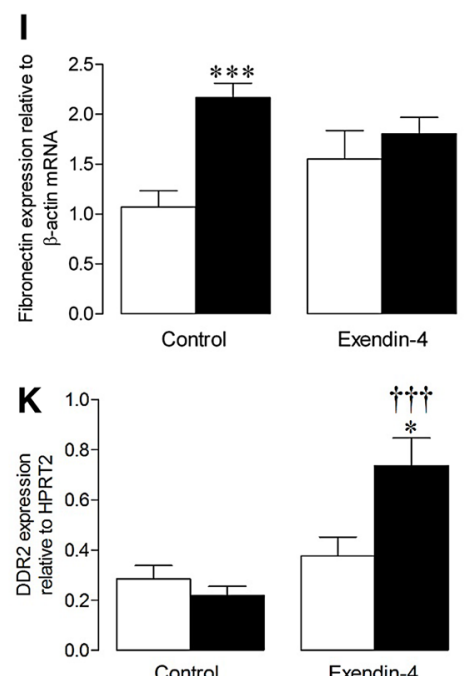

Fig. 3 Effect of exendin-4 on ECM remodelling after MI. ad Representative LV sections stained with picrosirius red to assess interstitial fibrosis, e quantification data $(n=6)$. $\mathbf{f}-\mathbf{j}$ mRNA expression of ECM genes by real-time RT-PCR $(n=5-12), \mathbf{k}$ DDR2 protein expression by Western blot $(n=6)$. White columns sham; black columns MI; mean \pm SEM. $* P<0.05$, $* * P<0.01$, ***P $P<0.001$, versus corresponding sham; ${ }^{\dagger} P<0.05$, ${ }^{\dagger \dagger} P<0.001$, MI exendin- 4 versus MI control 


\section{A Sham control}
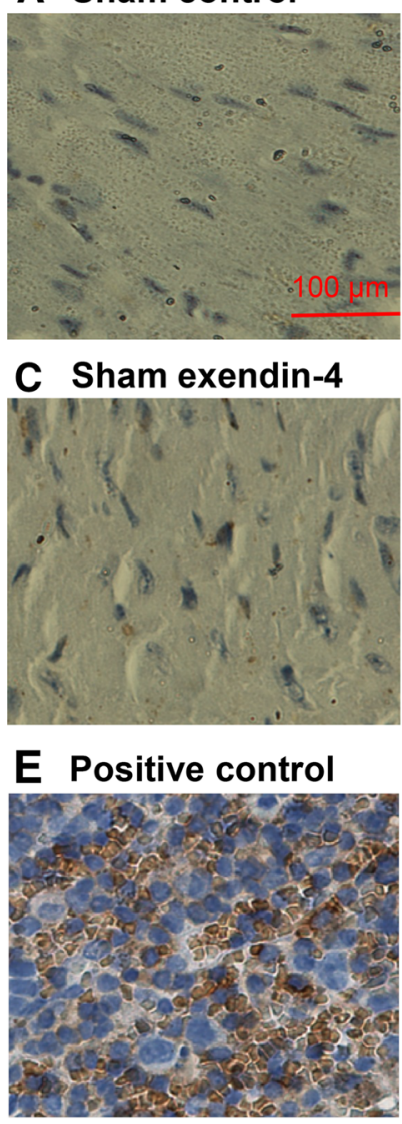

\section{B MI control}

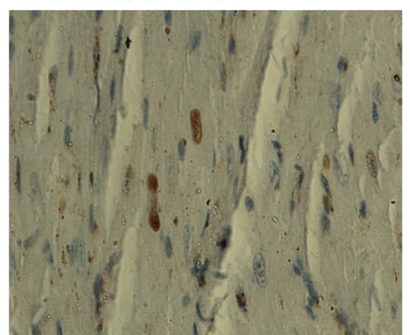

D Ml exendin-4

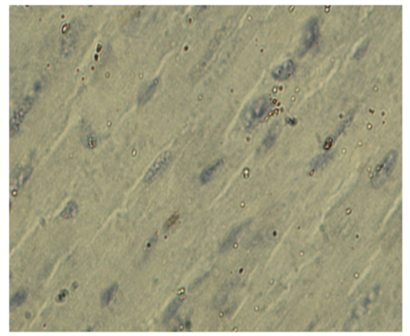

$\mathbf{F}$

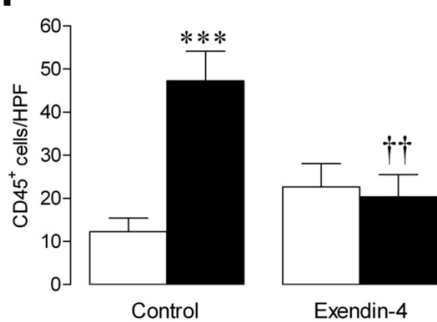

Fig. 4 Effect of exendin-4 on myocardial inflammation after MI. Representative LV sections stained for a-e CD45, with positive spleen control, and $\mathbf{g}-\mathbf{j}$ F4/80, to assess leukocyte and macrophage infiltration, respectively. f, k Quantification data $(n=5-6)$. White

$\beta$ signalling and ECM turnover with documented cardioprotective actions [41, 42], were specifically modulated by exendin-4 post-MI. MI-induced decreases in both total and phosphorylated Smad2 and Smad3 were prevented by exendin-4, although the drug itself also reduced total protein expression in shams (Fig. 6a-f).

\section{Cell studies}

To investigate cell-specific effects of exendin- 4 relevant to post-MI remodelling, a series of mechanistic studies were conducted in murine cardiac fibroblasts and BMDM. Exendin- 4 had no effect on basal and TGF- $\beta$-stimulated $\alpha$ SMA and CTGF expression in cardiac fibroblasts (Fig. 7ac). In addition, actin myofilament density, visualised by $\alpha$ SMA staining, was similar between fibroblasts treated with/without TGF- $\beta$ in the presence/absence of exendin-4 (Fig. 7d-g), confirming that exendin-4 does not appear to exert direct effects on these cells. Further studies confirmed previous reports that cardiac fibroblasts do not express the

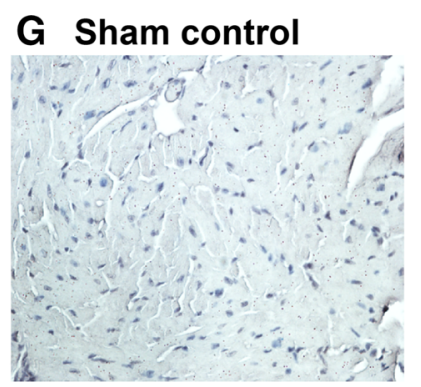

\section{Sham exendin-4}
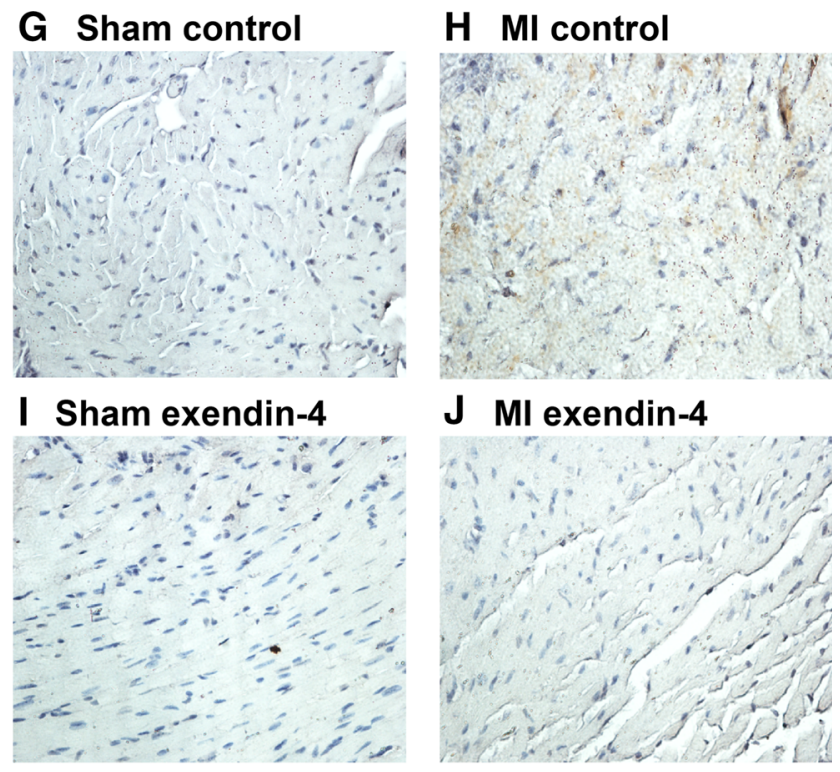

J Ml exendin-4
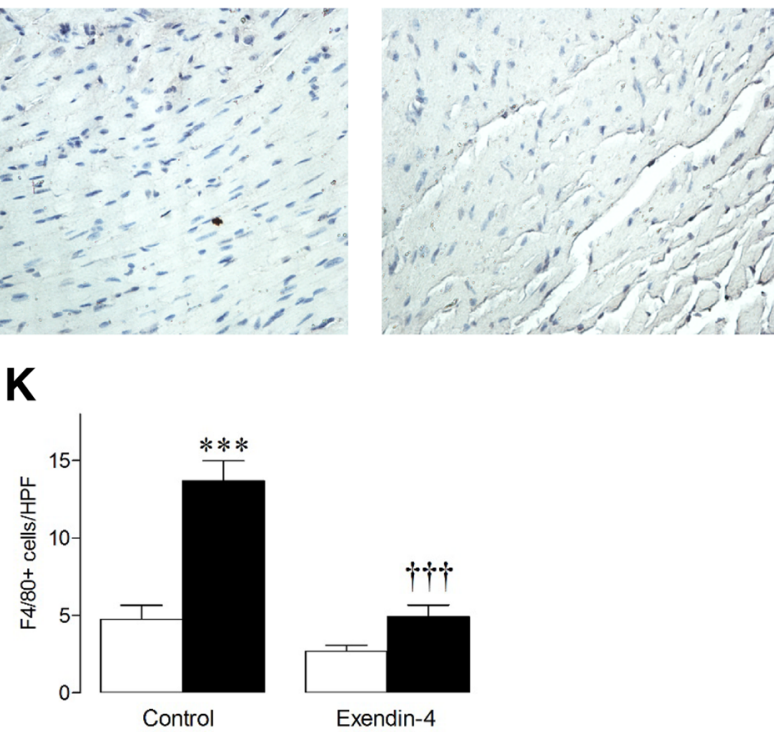

columns sham; black columns $\mathrm{MI} ;$ mean \pm SEM. $* * * P<0.001$, versus corresponding sham; ${ }^{\dagger} P<0.01,{ }^{\dagger \dagger} P<0.001$, MI exendin-4 versus MI control

GLP-1R [8], whilst significant GLP-1R expression was detected in BMDM which appeared to be increased by exendin-4 (Online Resource 6). Notably, treatment of BMDM with exendin- 4 for $24 \mathrm{~h}$ resulted in modulation of several macrophage response genes relevant to tissue repair/remodelling. Cellular mRNA expression of CD11b, MMP-9 and FGF- 2 was reduced with that of IL-10, IL-1- $\beta$, and CCL2 increased (Fig. 8a-f), whilst levels of key secreted proteins (CXCL10, CXCL1, CCL2, TIMP-1) were decreased by exendin-4 (Fig. 8g, h).

\section{Discussion}

Here, it is reported for the first time that chronic GLP-1R activation post-MI protects against adverse ventricular remodelling via specific actions on individual remodelling components which appear to involve preferential targeting of inflammation and the ECM. This study clearly demonstrates that exendin- 4 protects against cardiac contractile 
A SHAM-CON MI-CON SHAM-EX4 MI-EX4
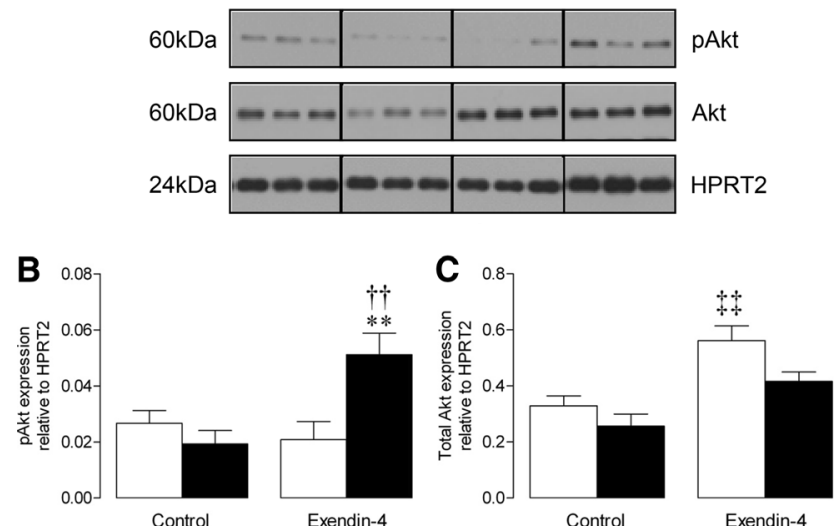

Fig. 5 Effect of exendin-4 on Akt and GSK3 $\beta$ expression after MI. Representative Western blots for total and phosphorylated a Akt, and d GSK-3 $\beta$; blots were stripped and reprobed and normalised to HPRT2, which is displayed within each panel for comparison. b, c, e,
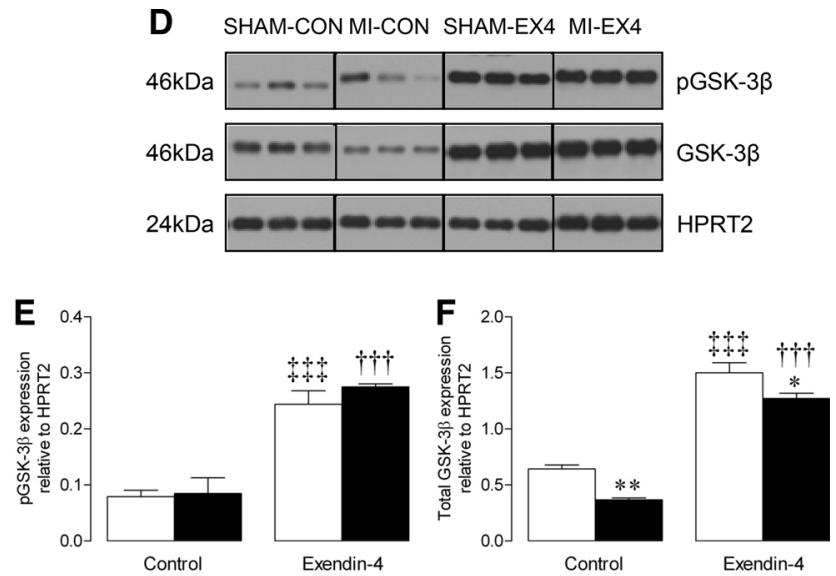

f Quantification data $(n=6)$. White columns sham; black columns MI; mean \pm SEM. $* P<0.05, * * P<0.01$, versus corresponding sham; ${ }^{\dagger \dagger} P<0.01,{ }^{\dagger \dagger} P<0.001$, MI exendin- 4 versus MI control; ${ }^{*} P<0.01,{ }^{*} P<0.001$, sham exendin-4 versus sham control
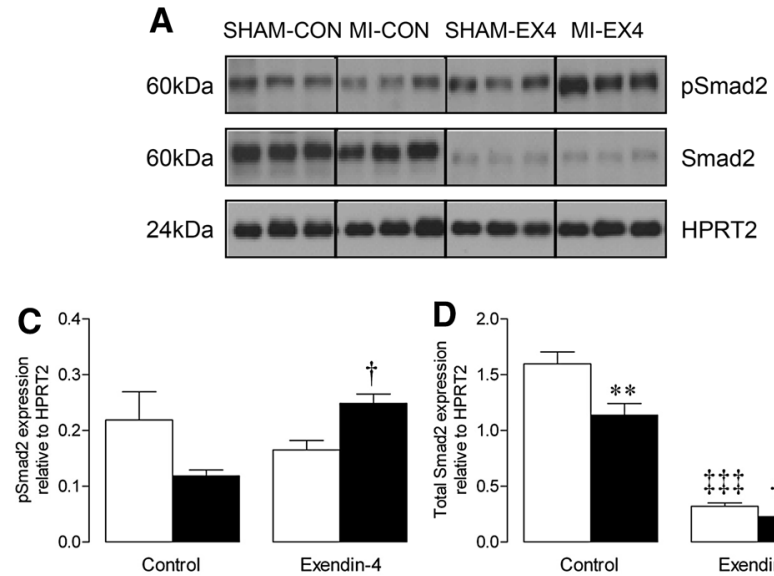

Fig. 6 Effect of exendin-4 on Smad2/3 expression after MI. Representative Western blots for total and phosphorylated a Smad2, and d Smad3; blots were stripped and reprobed and normalised to HPRT2, which is displayed within each panel for comparison. b-c, e-

dysfunction after experimental MI, which is associated with reduced cardiomyocyte hypertrophy/apoptosis, and marked attenuation of myocardial inflammation and ECM remodelling. Importantly, these beneficial effects on postMI remodelling occurred independently of the established glycaemic and acute cardioprotective actions of GLP-1 and were associated with modulation of both Akt/GSK-3 $\beta$ and Smad $2 / 3$ signalling and improved survival. Furthermore, complementary cell studies found that exendin-4 modulated macrophage response gene expression and protein secretion, but had no effect on differentiation of cardiac fibroblasts, which do not express the GLP-1R, suggesting that the observed actions on ECM remodelling may occur secondary to modulation of myocardial
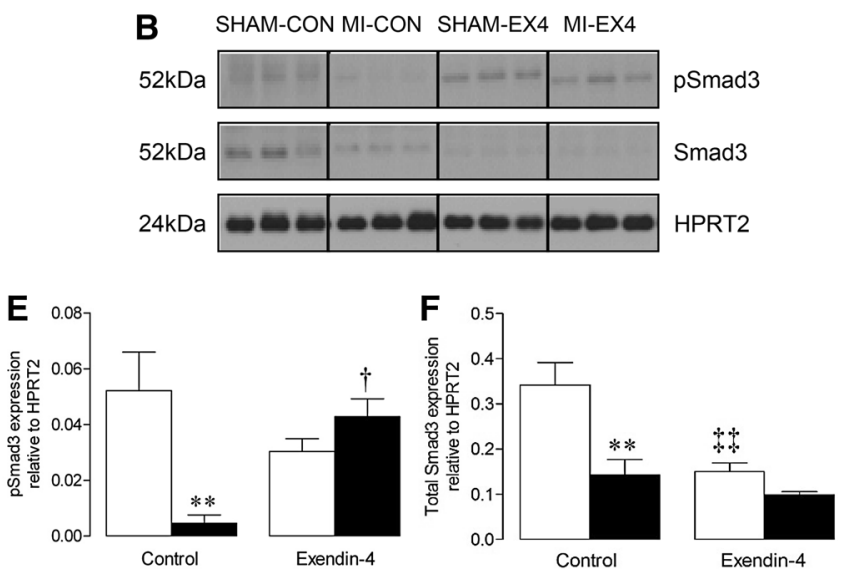

f Quantification data $(n=6)$. White columns sham; black columns MI; mean \pm SEM. $\quad * * P<0.01$, versus corresponding sham; ${ }^{\dagger} P<0.05,{ }^{\dagger \dagger} P<0.001, \quad$ MI exendin-4 versus MI control; ${ }^{\mathrm{N}} P<0.01,{ }^{\mathrm{N}} P<0.001$, sham exendin-4 versus sham control

inflammation, although it is likely that cardiomyocyte signalling pathways are also involved.

The rationale for this investigation was based on several studies indicating that GLP-1R activation confers protection against acute ischaemic damage $[8,19,20]$ and two subsequent reports that GLP-1 analogues administered 2 days and 2 weeks post-MI improve survival and cardiac structure/function [23, 43]. Here, we chose to employ an alternate treatment regimen of continuous exendin-4 infusion starting immediately after MI or sham surgery to specifically assess effects on distinct aspects of post-MI remodelling independently of GLP-1R-mediated alterations in acute infarct remodelling. Indeed, area at risk and infarct size measurements were comparable between 

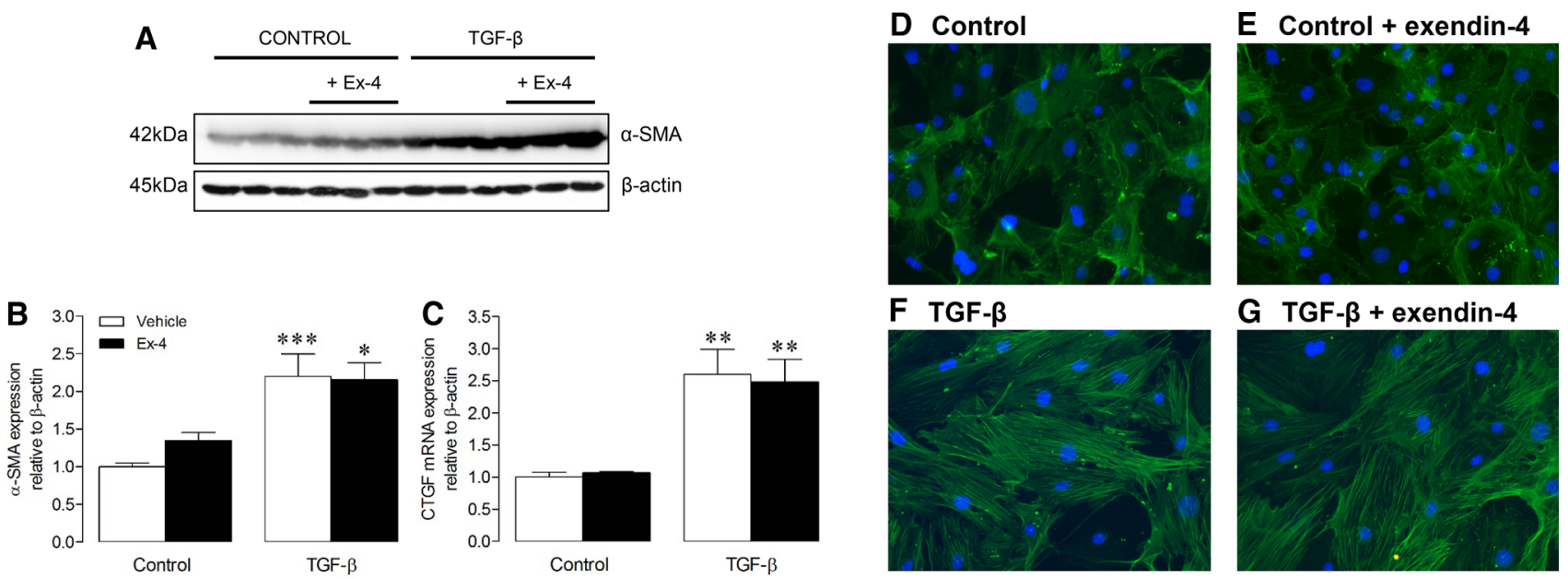

Fig. 7 Effect of exendin-4 on isolated murine cardiac fibroblasts. a Representative Western blot for $\alpha$-SMA in cardiac fibroblasts treated with/without TGF- $\beta(5 \mathrm{ng} / \mathrm{ml})$ in the presence/absence of exendin-4 (Ex-4; $10 \mathrm{nmol} / \mathrm{L})$ for $24 \mathrm{~h}$; blots were stripped and reprobed and normalised to $\beta$-actin. $\mathbf{b} \alpha$-SMA protein quantification data $(n=8)$. c CTGF mRNA expression in cardiac fibroblasts by real-time RT-PCR $(n=6)$. d-g Representative images of cardiac fibroblasts stained for $\alpha$-SMA to visualise myofibroblast differentiation with DAPI nuclear counterstaining. Data are mean \pm SEM. $* P<0.05, * * P<0.01 ; * * * P<0.001$, versus corresponding control
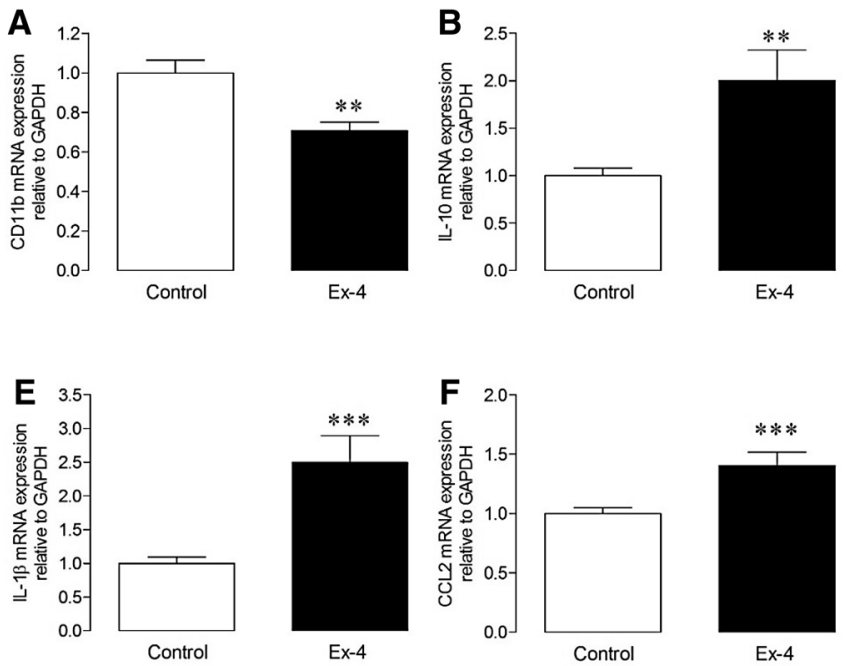

Fig. 8 Effect of exendin-4 on inflammatory gene expression in isolated BMDM. a-f Cellular mRNA expression by real-time RTPCR $(n=6-8)$, and $\mathbf{g}, \mathbf{h}$ conditioned media cytokine protein array

groups indicating that the observed effects were likely to be due to direct actions on post-MI ventricular remodelling. Importantly, the concentration of exendin- 4 employed in our study was comparable to those commonly used in previous rodent studies relating to the anti-diabetic and cardioprotective actions of GLP-1 [12, 15, 16, 32]. Furthermore, our studies were performed in wild-type mice, in which body weight and circulating glucose, insulin and lipids were unaltered by exendin-4, together with minimal changes in adipokine expression, suggesting that the reported cardiac effects are likely to be due to direct actions
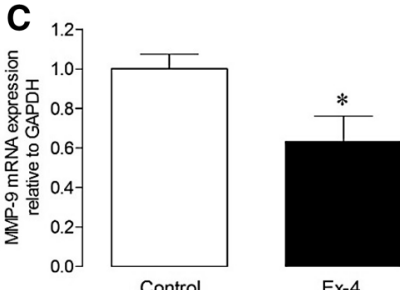

G

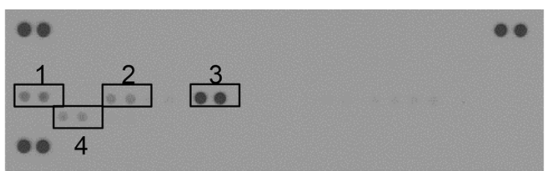

H

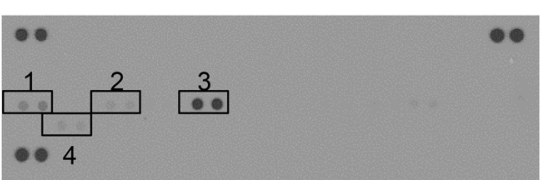

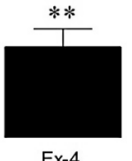

(1) $\mathrm{CXCL} 10$

(2) CXCL1

(3) CCL2

(4) TIMP-1 blots, of macrophage response genes from BMDM treated with/ without exendin-4 (Ex-4; $1 \mathrm{nmol} / \mathrm{L})$ for $24 \mathrm{~h}$. Data are mean $\pm \mathrm{SEM}$. $* P<0.05, * * P<0.01 ; * * * P<0.001$, versus corresponding control

of exendin-4, although it is impossible to completely exclude peripheral effects.

Several previous studies have indicated that GLP-1 modulates basal cardiac function and protects against contractile dysfunction associated with both experimental and clinical CHF [10, 13, 14, 16, 18, 21, 22]. Indeed in our study, the development of MI-induced systolic dysfunction (increased LVESV, decreased ejection fraction and $\left.\operatorname{LVd} P \mathrm{~d} t_{\max }\right)$ was attenuated by exendin-4. Chronic treatment with exendin-4 also improved LV relaxation after MI (increased $\mathrm{LVd} P / \mathrm{d} t_{\min }$, reduced $\tau$ ) and protected against 
diastolic dysfunction (preserved mitral valve $E / A$ ratio, reduced LV end-diastolic pressure). Furthermore, LV dilatation (measured by LVEDD and LVEDV) observed in MI control mice was reduced by exendin-4.

It seems reasonable to conclude that the marked attenuation of cardiac contractile dysfunction by exendin-4 post-MI occurred secondary to beneficial actions on both the cardiomyocyte and ECM, which are established as key remodelling components in this setting [3]. Indeed, exendin-4 caused modest reductions in morphometric heart/body weight and cardiomyocyte cross-sectional area after MI, together with reduced in vivo cardiomyocyte apoptosis. Acute exendin-4 treatment also inhibited in vitro phenylephrine-induced $\mathrm{H} 9 \mathrm{c} 2$ cardiomyoblast hypertrophy but failed to reduce doxorubicin-induced apoptosis of HL-1 cardiomyocytes, assessed by caspase 3/7 activation. However, it is important to highlight that our conducted assessment of cardiomyocyte apoptosis was minimal as only a single output was measured in both ventricular tissue and cultured cells which represents a significant limitation. Nonetheless, other studies have consistently shown GLP-1 to protect cardiomyocytes from apoptosis both in vivo and in vitro $[15,30]$, although reported effects on cardiomyocyte hypertrophy have been varied. Whilst some have reported the DPP-4 inhibitor, sitagliptin, and exendin-4 to have no effect on cardiomyocyte hypertrophy in experimental MI and type 1 diabetes, respectively, others have shown that GLP-1R activation with liraglutide reduces cardiomyocyte hypertrophy after both $\mathrm{MI}$ and high-fat feeding [15, 44-46]. Therefore, it is maybe not surprising that exendin-4 exerted only modest effects on post-MI cardiomyocyte remodelling, which may have occurred directly or secondary to more pronounced effects on the ECM.

Indeed, contractile function is particularly sensitive to ECM remodelling, and exendin-4 markedly reduced MIinduced increases in interstitial fibrosis and ECM gene expression, which is likely to significantly contribute to the associated improvement of $\mathrm{LV}$ relaxation $\left(\mathrm{LVd} P / \mathrm{d} t_{\min }, \tau\right)$ and tendency towards increased diastolic function (mitral valve $E / A$ ratio, $\mathrm{LV}$ end-diastolic pressure). Interestingly, this was associated with marked increases in myocardial expression of DDR2 in MI exendin-4 animals, which is an established fibroblast marker also known to modulate collagen biosynthesis [37, 38]. As far as we are aware, these data provide the first direct evidence that GLP-1R activation modulates ECM remodelling, a finding which may have important implications for the use of GLP-1-based therapies in diabetic patients, who are frequently characterised by a disproportionate accumulation of collagen within the heart [47]. Interestingly, our complementary studies in cardiac fibroblasts found that exendin-4 had no effect on TGF- $\beta$-induced cell differentiation, which is maybe not surprising as cardiac fibroblasts are known not to express the GLP-1R [8], and suggests that the observed effects on ECM remodelling may be mediated via another cell type. Indeed, we found that myocardial GLP-1R expression was increased after MI (which may represent an adaptive response) and was normalised by exendin-4, although it is also possible that the mechanism may involve established GLP-1R-independent pathways [8, 48].

The most likely remodelling process by which exendin4 may mediate indirect effects on the cardiac fibroblast would appear to be inflammation, which is becoming increasingly recognised as an important mediator of post-MI remodelling capable of exerting specific regulatory actions on several remodelling components, but which preferentially targets the ECM [43, 49]. Indeed, in this study, experimental MI was associated with marked myocardial infiltration of $\mathrm{CD} 45^{+}$leukocytes and $\mathrm{F} 4 / 80^{+}$macrophages and altered expression of inflammatory cytokines, IL-10 (known regulator of tissue remodelling), IL-1 $\beta$ and IL-6 (both critical for fibroblast differentiation) [50, 51]. Importantly, exendin-4 completely prevented these changes suggesting that the observed benefits on post-MI remodelling may have occurred, at least partly, secondary to modulation of inflammation, which is consistent with previous reports of anti-inflammatory actions in other organs, such as the pancreas [29]. Furthermore, complementary experiments in BMDM, which expressed the GLP-1R, found that exendin-4 differentially modulated basal levels of both resident and secreted macrophage response genes, which are known to contribute to tissue remodelling and repair [52, 53]. Exendin-4 decreased macrophage expression of both CD11b, which plays a key role in monocyte adhesion, and MMP-9 and FGF-2 which are important drivers of ECM remodelling, whilst tissueprotective IL-10 and pro-inflammatory IL-1 $\beta$ and CCL2 were upregulated. Furthermore, exendin-4 reduced levels of secreted CXCL10, CXCL1, CCL2 and TIMP-1, all of which are key modulators of macrophage function [49]. Taken together, these data clearly suggest that the observed effects of exendin-4 on ECM remodelling are mediated, at least partly via indirect macrophage-driven actions on the cardiac fibroblast. However, the underlying mechanisms are likely to be complex and require detailed further investigation.

As previous studies focusing on the acute cardioprotective actions of GLP-1 have consistently demonstrated modulation of both Akt and GSK-3 $\beta$ [15, 16, 20], we chose to investigate effects of exendin-4 on this pathway in the setting of post-MI remodelling. Indeed, in our study, Akt and also GSK-3 $\beta$, which has been reported to specifically suppress cardiac fibroblast-mediated remodelling [39], were upregulated by exendin- 4 after MI, at both total and phosphorylated protein level, suggesting that modulation of 
cardiomyocyte Akt/GSK-3 $\beta$ signalling plays a key role in mediating the chronic cardioprotective actions of GLP-1R activation and may thereby indirectly influence ECM remodelling. Notably, chronic cardiomyocyte-specific Akt activation has recently been shown to promote both pathological hypertrophy and fibrosis [54], supporting the suggestion that exendin- 4 induced modulation of cardiomyocyte Akt/GSK-3 $\beta$ signalling may contribute to the observed ECM effects. In addition to its effects on Akt/ GSK-3 $\beta$ signalling, exendin- 4 prevented MI-induced decreases in phosphorylated Smad2 and Smad3, indicating that it may promote activity of these two key Smad proteins in the viable myocardium post-MI. Although Smad2 and Smad3 signalling are closely linked [40], their precise role in cardiac remodelling is unknown. For example, some studies indicate that they may exert divergent cardiac actions, with Smad3 being pro-fibrotic and Smad2 protective against cardiomyocyte remodelling, whereas others suggest that cardiac fibrosis is promoted by $\mathrm{Smad} 2$ and inhibited by Smad3 [39, 41, 55, 56]. Interestingly, other groups have also questioned the dependence of cardiac Smad signalling on TGF- $\beta$ [57, 58]. Therefore, although it appears that exendin- 4 exerts its benefits on post-MI remodelling, at least partly via activation of $\operatorname{Smad} 2 / 3$, the precise nature of these actions remains unclear.

Although our data clearly suggest that exendin- 4 exerts distinct protective actions on post-MI remodelling via apparently preferential modulation of myocardial inflammation and the ECM, it is important to consider several limitations. A major issue with such studies is the inherent risk of selection bias as only surviving animals are studied, so it is possible that infarcts may have been larger in MI controls thereby explaining their tendency towards increased mortality. However, MI animals generally died within 7 days due to cardiac rupture, as opposed to acute heart failure, which is more likely to reflect impaired wound healing, and further to our 4-week data, may indeed be expected to be improved by exendin- 4 . In addition, as exendin- 4 was infused immediately post-MI, it seems unlikely that this treatment would affect area at risk and extent of infarction. In this regard, it should be noted that sample numbers were not consistently lower in MI control versus exendin- 4 treated animals and that any disparities were due to practical or technical issues. There are also potential limitations with our experimental model. Firstly, while there is a general argument that both sexes should be included in disease investigation, only female mice were assessed here due to animal welfare considerations. Indeed, we have previously employed female mice for post-MI remodelling studies as have several other leading groups $[31,59,60]$. Secondly, we chose to induce permanent coronary artery ligation and so the influence of reperfusion could not be studied. Thirdly, we used a supra-clinical dose of exendin- 4 to identify specific remodelling actions and effects of lower therapeutic levels were not assessed. Furthermore, as our initial aim was to precisely define the actions of exendin- 4 on post-MI remodelling by focussing on individual components, no primary end point was selected. It is also important to recognise that the use of cell lines to interrogate in vitro effects of exendin- 4 on cardiomyocyte hypertrophy may have limited relevance to the in vivo setting, although they may still provide useful complementary data. Nonetheless, our findings indicate that exendin- 4 protects against post-MI remodelling and promotes preferential modulation of the ECM. However, although our in vivo data show clear differences in myocardial inflammation and our in vitro data suggest that macrophage signalling may be a potential target for exendin- 4 in this setting, we cannot conclude that the observed ECM effects are specifically mediated via macrophage/fibroblast interaction without more sophisticated in vitro and in vivo studies. Similarly, the effects of exendin- 4 on cardiomyocyte signalling pathways need to be further interrogated to establish their precise influence on post-MI remodelling.

Despite these limitations, our data strongly suggest that exendin-4 exerts distinct protective actions on post-MI remodelling, independent of its established metabolic and glycaemic effects, which appear to be mediated via preferential modulation of myocardial inflammation and the ECM. Whilst noting that cardiomyocyte signalling pathways are also altered by exendin- 4 and so are likely to directly or indirectly influence post-MI remodelling, our findings clearly indicate that exendin- 4 exerts distinct actions on specific aspects of post-MI remodelling, and together with previous studies reporting both acute and chronic cardioprotective effects, highlight the potential of GLP-1-based therapeutic strategies. In this regard, it should be noted that the first large-scale GLP-1 cardiovascular trials recently reported that the DPP-4 inhibitors, saxagliptin and alogliptin, did not confer cardiovascular benefit in type 2 diabetes [61, 62], although there are currently no data from long-term randomised clinical trials with GLP-1R agonists, with several ongoing [7]. Although circulating GLP-1 levels in patients treated with DPP-4 inhibitors are much lower than those achieved using GLP$1 \mathrm{R}$ agonists, the seemingly disappointing results of these recent trials would appear to support our suggestion that a more selective approach targeted towards specific post-MI remodelling components may be required to realise the clear potential of GLP-1-based strategies in this setting.

Acknowledgments This work was supported by research grants from the British Heart Foundation (PG/09/102), Diabetes UK (RD06/ 0003272) and the Medical Research Council (G0601215).

Conflict of interest None. 
Open Access This article is distributed under the terms of the Creative Commons Attribution License which permits any use, distribution, and reproduction in any medium, provided the original author(s) and the source are credited.

\section{References}

1. Bell DS (2008) Diabetes: a cardiac condition manifesting as hyperglycemia. Endocr Pract 14:924-932. doi:10.4158/EP.14.7. 924

2. Bertoia ML, Waring ME, Gupta PS, Roberts MB, Eaton CB (2011) Implications of new hypertension guidelines in the United States. Hypertension 58:361-366. doi:10.1161/HYPERTENSIO NAHA.111.175463

3. Heusch G, Libby P, Gersh B, Yellon D, Bohm M, Lopaschuk G, Opie L (2014) Cardiovascular remodelling in coronary artery disease and heart failure. Lancet 383:1933-1943. doi:10.1016/ S0140-6736(14)60107-0

4. Braunwald E (2013) Heart Failure. JACC. Heart Fail 1:1-20. doi:10.1016/j.jchf.2012.10.002

5. Chen J, Hsieh AF, Dharmarajan K, Masoudi FA, Krumholz HM (2013) National trends in heart failure hospitalization after acute myocardial infarction for Medicare beneficiaries: 1998-2010. Circulation 128:2577-2584. doi:10.1161/CIRCULATIONAHA. 113.003668

6. Grieve DJ, Cassidy RS, Green BD (2009) Emerging cardiovascular actions of the incretin hormone glucagon-like peptide-1: potential therapeutic benefits beyond glycaemic control? $\mathrm{Br} \mathrm{J}$ Pharmacol 157:1340-1351. doi:10.1111/j.1476-5381.2009. 00376.x

7. Tate M, Chong A, Robinson E, Green BD, Grieve DJ (2015) Selective targeting of glucagon-like peptide-1 signalling as a novel therapeutic approach for cardiovascular disease in diabetes. Br J Pharmacol 172:721-736. doi:10.1111/bph.12943

8. Ban K, Noyan-Ashraf MH, Hoefer J, Bolz SS, Drucker DJ, Husain M (2008) Cardioprotective and vasodilatory actions of glucagon-like peptide 1 receptor are mediated through both glucagon-like peptide 1 receptor-dependent and -independent pathways. Circulation 117:2340-2350. doi:10.1161/CIRCULA TIONAHA.107.739938

9. Green BD, Hand KV, Dougan JE, McDonnell BM, Cassidy RS (2008) Grieve DJ (2008) GLP-1 and related peptides cause concentration-dependent relaxation of rat aorta through a pathway involving KATP and cAMP. Arch Biochem Biophys 478:136-142. doi:10.1016/j.abb.2008.08.001

10. Gros R, You X, Baggio LL, Kabir MG, Sadi AM, Mungrue IN, Parker TG, Huang Q, Drucker DJ, Husain M (2003) Cardiac function in mice lacking the glucagon-like peptide-1 receptor. Endocrinology 144:2242-2252. doi:10.1210/en.2003-0007

11. Vila Petroff MG, Egan JM, Wang X, Sollott SJ (2001) Glucagonlike peptide-1 increases cAMP but fails to augment contraction in adult rat cardiac myocytes. Circ Res 89:445-452. doi:10.1161/ hh1701.095716

12. Yamamoto H, Lee CE, Marcus JN, Williams TD, Overton JM, Lopez ME, Hollenberg AN, Baggio L, Saper CB, Drucker DJ, Elmquist JK (2002) Glucagon-like peptide-1 receptor stimulation increases blood pressure and heart rate and activates autonomic regulatory neurons. J Clin Invest 110:43-52. doi:10.1172/ JCI15595

13. Goodwill A, Tune J, Noblet J, Conteh A, Sassoon D, Casalini E, Mather K (2014) Glucagon-like peptide-1 (7-36) but not (9-36) augments cardiac output during myocardial ischemia via a Frank-
Starling mechanism. Basic Res Cardiol 109:426. doi:10.1007/ s00395-014-0426-9

14. Nikolaidis LA, Elahi D, Hentosz T, Doverspike A, Huerbin R, Zourelias L, Stolarski C, Shen YT, Shannon RP (2004) Recombinant glucagon-like peptide-1 increases myocardial glucose uptake and improves left ventricular performance in conscious dogs with pacing-induced dilated cardiomyopathy. Circulation 110:955-961. doi:10.1161/01.CIR.0000139339.85840.DD

15. Noyan-Ashraf MH, Momen MA, Ban K, Sadi AM, Zhou YQ, Riazi AM, Baggio LL, Henkelman RM, Husain M, Drucker DJ (2009) GLP-1R agonist liraglutide activates cytoprotective pathways and improves outcomes after experimental myocardial infarction in mice. Diabetes 58:975-983. doi:10.2337/db08-1193

16. Poornima I, Brown S, Bhashyam S, Parikh P, Bolukoglu H, Shannon RP (2008) Chronic glucagon-like peptide-1 (GLP-1) infusion sustains LV systolic function and prolongs survival in the spontaneously hypertensive-heart failure prone rat. Circ Heart Fail 1:153-160. doi:10.1161/CIRCHEARTFAILURE.108.766402

17. Sauve M, Ban K, Momen MA, Zhou YQ, Henkelman RM, Husain M, Drucker DJ (2010) Genetic deletion or pharmacological inhibition of dipeptidyl peptidase-4 improves cardiovascular outcomes following myocardial infarction in mice. Diabetes 59:1063-1073. doi:10.2337/db09-0955

18. Sokos GG, Nikolaidis LA, Mankad S, Elahi D, Shannon RP (2006) Glucagon-like peptide-1 infusion improves left ventricular ejection fraction and functional status in patients with chronic heart failure. J Card Fail 12:694-699. doi:10.1016/j.cardfail. 2006.08.211

19. Bose AK, Mocanu MM, Carr RD, Brand CL, Yellon DM (2005) Glucagon-like peptide 1 can directly protect the heart against ischemia/reperfusion injury. Diabetes 54:146-151. doi:10.2337/ diabetes.54.1.146

20. Timmers L, Henriques JP, de Kleijn DP, Devries JH, Kemperman H, Steendijk P, Verlaan CW, Kerver M, Piek JJ, Doevendans PA, Pasterkamp G, Hoefer IE (2009) Exenatide reduces infarct size and improves cardiac function in a porcine model of ischemia and reperfusion injury. J Am Coll Cardiol 53:501-510. doi:10.1016/j. jacc.2008.10.033

21. Liu Q, Anderson C, Broyde A, Polizzi C, Fernandez R, Baron A, Parkes D (2010) Glucagon-like peptide-1 and the exenatide analogue AC3174 improve cardiac function, cardiac remodeling, and survival in rats with chronic heart failure. Cardiovasc Diabetol 9:76. doi:10.1186/1475-2840-9-76

22. Nikolaidis LA, Mankad S, Sokos GG, Miske G, Shah A, Elahi D, Shannon RP (2004) Effects of glucagon-like peptide-1 in patients with acute myocardial infarction and left ventricular dysfunction after successful reperfusion. Circulation 109:962-965. doi:10. 1161/01.CIR.0000120505.91348.58

23. DeNicola M, Du J, Wang Z, Yano N, Zhang L, Wang Y, Qin G, Zhuang S, Zhao TC (2014) Stimulation of glucagon-like peptide1 receptor through exendin- 4 preserves myocardial performance and prevents cardiac remodeling in infarcted myocardium. Am J Physiol Endocrinol Metab 307:E630-E643. doi:10.1152/ajpendo. 00109.2014

24. Ussher JR, Baggio LL, Campbell JE, Mulvihill EE, Kim M, Kabir MG, Cao X, Baranek BM, Stoffers DA, Seeley RJ, Drucker DJ (2014) Inactivation of the cardiomyocyte glucagon-like peptide-1 receptor (GLP-1R) unmasks cardiomyocyte-independent GLP-1R-mediated cardioprotection. Mol Metab 3:507-517. doi:10.1016/j.molmet.2014.04.009

25. Arnette D, Gibson TB, Lawrence MC, January B, Khoo S, McGlynn K, Vanderbilt CA, Cobb MH (2003) Regulation of ERK1 and ERK2 by glucose and peptide hormones in pancreatic $\beta$ cells. J Biol Chem 278:32517-32525. doi:10.1074/jbc. M301174200 
26. Kim S, Moon M, Park S (2009) Exendin-4 protects dopaminergic neurons by inhibition of microglial activation and matrix metalloproteinase-3 expression in an animal model of Parkinson's disease. J Endocrinol 202:431-439. doi:10.1677/JOE-09-0132

27. Montrose-Rafizadeh C, Avdonin P, Garant MJ, Rodgers BD, Kole S, Yang H, Levine MA, Schwindinger W, Bernier M (1999) Pancreatic glucagon-like peptide-1 receptor couples to multiple G proteins and activates mitogen-activated protein kinase pathways in chinese hamster ovary cells. Endocrinology 140:1132-1140. doi:10.1210/endo.140.3.6550

28. Park CW, Kim HW, Ko SH, Lim JH, Ryu GR, Chung HW, Han SW, Shin SJ, Bang BK, Breyer MD, Chang YS (2007) Long-term treatment of glucagon-like peptide- 1 analog exendin-4 ameliorates diabetic nephropathy through improving metabolic anomalies in db/db mice. J Am Soc Nephrol 18:1227-1238. doi:10. 1681/ASN.2006070778

29. Pugazhenthi U, Velmurugan K, Tran A, Mahaffey G, Pugazhenthi S (2010) Anti-inflammatory action of exendin-4 in human islets is enhanced by phosphodiesterase inhibitors: potential therapeutic benefits in diabetic patients. Diabetologia 53:2357-2368. doi:10.1007/s00125-010-1849-y

30. Wu XM, Ou QY, Zhao W, Liu J, Zhang H (2014) The GLP-1 analogue liraglutide protects cardiomyocytes from high glucoseinduced apoptosis by activating the Epac-1/Akt pathway. Exp Clin Endocrinol Diabetes 122:608-614. doi:10.1055/s-00341384584

31. Looi YH, Grieve DJ, Siva A, Walker SJ, Anilkumar N, Cave AC, Marber M, Monaghan MJ, Shah AM (2008) Involvement of Nox2 NADPH oxidase in adverse cardiac remodeling after myocardial infarction. Hypertension 51:319-325. doi:10.1161/HYPERTEN SIONAHA.107.101980

32. Green BD, Lavery KS, Irwin N, O'Harte FP, Harriott P, Greer B, Bailey CJ, Flatt PR (2006) Novel GLP-1 analogue $\left(\mathrm{Val}^{8}\right)$ GLP-1 results in significant improvements of glucose tolerance and pancreatic beta cell function after 3 weeks daily administration in obese diabetic (ob/ob) mice. J Pharmacol Exp Ther 318:914-921. doi:10.1124/jpet.105.097824

33. Jeong K, Kwon H, Min C, Pak Y (2009) Modulation of the caveolin-3 localization to caveolae and STAT3 to mitochondria by catecholamine-induced cardiac hypertrophy in H9c2 cardiomyocytes. Exp Mol Med 41:226-235. doi:10.3858/emm.2009. 41.4.025

34. Kim Y, Ma AG, Kitta K, Fitch SN, Ikeda T, Ihara Y, Simon AR, Evans T, Suzuki YJ (2003) Anthracycline-induced suppression of GATA-4 transcription factor: implication in the regulation of cardiac myocyte apoptosis. Mol Pharmacol 63:368-377. doi:10. $1124 / \mathrm{mol} .63 .2 .368$

35. Takeda N, Manabe I, Uchino Y, Eguchi K, Matsumoto S, Nishimura S, Shindo T, Sano M, Otsu K, Snider P, Conway SJ, Nagai R (2010) Cardiac fibroblasts are essential for the adaptive response of the murine heart to pressure overload. J Clin Invest 120:254-265. doi:10.1172/JCI40295

36. Zhang X, Goncalves R, Mosser DM (2008) The isolation and characterization of murine macrophages. Curr Protoc Immunol Chapter: Unit 14.1. doi:10.1002/0471142735.im1401s83

37. Flynn LA, Blissett AR, Calomeni EP, Agarwal G (2010) Inhibition of collagen fibrillogenesis by cells expressing soluble extracellular domains of DDR1 and DDR2. J Mol Biol 395:533-543. doi:10.1016/j.jmb.2009.10.073

38. Haudek SB, Cheng J, Du J, Wang Y, Hermosillo-Rodriguez J, Trial J, Taffet GE, Entman ML (2010) Monocytic fibroblast precursors mediate fibrosis in angiotensin-II-induced cardiac hypertrophy. J Mol Cell Cardiol 49:499-507. doi:10.1016/j. yjmcc.2010.05.005

39. Lal H, Ahmad F, Zhou J, Yu JE, Vagnozzi RJ, Guo Y, Yu D, Tsai EJ, Woodgett J, Gao E, Force T (2014) Cardiac fibroblast glycogen synthase kinase-3 $\beta$ regulates ventricular remodeling and dysfunction in ischemic heart. Circulation 130:419-430. doi:10.1161/CIRCULATIONAHA.113.008364

40. Sugden PH, Fuller SJ, Weiss SC, Clerk A (2008) Glycogen synthase kinase 3 (GSK3) in the heart: a point of integration in hypertrophic signalling and a therapeutic target? A critical analysis. Br J Pharmacol 153(Suppl 1):S137-S153. doi:10.1038/sj. bjp.0707659

41. Divakaran V, Adrogue J, Ishiyama M, Entman ML, Haudek S, Sivasubramanian N, Mann DL (2009) Adaptive and maladaptive effects of SMAD3 signaling in the adult heart after hemodynamic pressure overloading. Circ Heart Fail 2:633-642. doi:10.1161/ CIRCHEARTFAILURE. 108.823070

42. Xu J, Kimball TR, Lorenz JN, Brown DA, Bauskin AR, Klevitsky R, Hewett TE, Breit SN, Molkentin JD (2006) GDF15/MIC-1 functions as a protective and antihypertrophic factor released from the myocardium in association with SMAD protein activation. Circ Res 98:342-350. doi:10.1161/01.RES.0000202804. 84885.d0

43. Lindner D, Zietsch C, Tank J, Sossalla S, Fluschnik N, Hinrichs S, Maier L, Poller W, Blankenberg S, Schultheiss HP, Tschope C, Westermann D (2014) Cardiac fibroblasts support cardiac inflammation in heart failure. Basic Res Cardiol 109:428. doi:10. 1007/s00395-014-0428-7

44. Hantouche CM, Bitar KM, Nemer GM, Obeid MY, Kadi LN, Der-Boghossian AH, Bikhazi AB (2010) Role of glucagon-like peptide-1 analogues on insulin receptor regulation in diabetic rat hearts. Can J Physiol Pharmacol 88:54-63. doi:10.1139/Y09-095

45. Mells JE, Fu PP, Sharma S, Olson DE, Cheng L, Handy JA, Saxena NK, Sorescu D, Anania FA (2011) GLP-1 analogue, liraglutide ameliorates hepatic steatosis and cardiac hypertrophy in C57BL/6J mice fed a western diet. Am J Physiol Gastrointest Liver Physiol 302:G225-G235. doi:10.1152/ajpgi.00274.2011

46. Ye Y, Keyes KT, Zhang C, Perez-Polo JR, Lin Y, Birnbaum Y (2010) The myocardial infarct size-limiting effect of sitagliptin is PKA-dependent, whereas the protective effect of pioglitazone is partially dependent on PKA. Am J Physiol Heart Circ Physiol 298:H1454-H1465. doi:10.1152/ajpheart.00867.2009

47. Asbun J, Villarreal FJ (2006) The pathogenesis of myocardial fibrosis in the setting of diabetic cardiomyopathy. J Am Coll Cardiol 47:693-700. doi:10.1016/j.jacc.2005.09.050

48. Sonne DP, Engstrom T, Treiman M (2008) Protective effects of GLP-1 analogues exendin-4 and GLP-1(9-36) amide against ischemia-reperfusion injury in rat heart. Regul Pept 146:243-249. doi:10.1016/j.regpep.2007.10.001

49. Kain V, Prabhu S, Halade G (2014) Inflammation revisited: inflammation versus resolution of inflammation following myocardial infarction. Basic Res Cardiol 109:444. doi:10.1007/ s00395-014-0444-7

50. Krishnamurthy P, Rajasingh J, Lambers E, Qin G, Losordo DW, Kishore R (2009) IL-10 inhibits inflammation and attenuates left ventricular remodeling after myocardial infarction via activation of STAT3 and suppression of HuR. Circ Res 104:e9-e18. doi:10. 1161/CIRCRESAHA.108.188243

51. Porter KE, Turner NA (2009) Cardiac fibroblasts: at the heart of myocardial remodeling. Pharmacol Ther 123:255-278. doi:10. 1016/j.pharmthera.2009.05.002

52. Arakawa M, Mita T, Azuma K, Ebato C, Goto H, Nomiyama T, Fujitani Y, Hirose T, Kawamori R, Watada H (2010) inhibition of monocyte adhesion to endothelial cells and attenuation of atherosclerotic lesion by a glucagon-like peptide-1 receptor agonist, exendin-4. Diabetes 59:1030-1037. doi:10.2337/db091694

53. Troidl C, Mollmann H, Nef H, Masseli F, Voss S, Szardien S, Willmer M, Rolf A, Rixe J, Troidl K, Kostin S, Hamm C, Elsässer A (2009) Classically and alternatively activated 
macrophages contribute to tissue remodelling after myocardial infarction. J Cell Mol Med 13:3485-3496. doi:10.1111/j.15824934.2009.00707.x

54. Wende AR, O'Neill BT, Bugger H, Riehle C, Tuinei J, Buchanan J, Tsushima K, Wang L, Caro P, Guo A, Sloan C, Kim BJ, Wang X, Pereira RO, McCrory MA, Nye BG, Benavides GA, DarleyUsmar VM, Shioi T, Weimer BC, Abel ED (2015) Enhanced cardiac Akt/protein kinase B signaling contributes to pathological cardiac hypertrophy in part by impairing mitochondrial function via transcriptional repression of mitochondrion-targeted nuclear genes. Mol Cell Biol 35:831-846. doi:10.1128/MCB.01109-14

55. de Boer RA, Pokharel S, Flesch M, van Kampen DA, Suurmeijer AJ, Boomsma F, van Gilst WH, van Veldhuisen DJ, Pinto YM (2004) Extracellular signal regulated kinase and SMAD signalling both mediate the angiotensin II driven progression towards overt heart failure in homozygous TGR(mRen2)27. J Mol Med 82:678-687. doi:10.1007/s00109-004-0579-3

56. Takuwa N, Ohkura SI, Takashima SI, Ohtani K, Okamoto Y, Tanaka T, Hirano K, Usui S, Wang F, Du W, Yoshioka K, Banno Y, Sasaki M, Ichi I, Okamura M, Sugimoto N, Mizugishi K, Nakanuma Y, Ishii I, Takamura M, Kaneko S, Kojo S, Satouchi K, Mitumori K, Chun J, Takuwa Y (2010) S1P3-mediated cardiac fibrosis in sphingosine kinase 1 transgenic mice involves reactive oxygen species. Cardiovasc Res 85:484-493. doi:10.1093/cvr/ cvp312

57. Li L, Okada H, Takemura G, Ki Kosai, Kanamori H, Esaki M, Takahashi T, Goto K, Tsujimoto A, Maruyama R, Kawamura I, Kawaguchi T, Takeyama T, Fujiwara T, Fujiwara H, Minatoguchi S (2009) Postinfarction gene therapy with adenoviral vector expressing decorin mitigates cardiac remodeling and dysfunction. Am J Physiol Heart Circ Physiol 297:H1504H1513. doi:10.1152/ajpheart.00194.2009

58. Zhang D, Gaussin V, Taffet GE, Belaguli NS, Yamada M, Schwartz RJ, Michael LH, Overbeek PA, Schneider MD (2000) TAK1 is activated in the myocardium after pressure overload and is sufficient to provoke heart failure in transgenic mice. Nat Med 6:556-563. doi:10.1038/75037

59. Hofmann U, Knorr S, Vogel B, Weirather J, Frey A, Ertl G, Frantz S (2014) Interleukin-13 deficiency aggravates healing and remodeling in male mice after experimental myocardial infarction. Circ Heart Fail 7:822-830. doi:10.1161/CIRCHEARTFAI LURE.113.001020

60. Ong SG, Lee WH, Huang M, Dey D, Kodo K, Sanchez-Freire V, Gold JD, Wu JC (2014) Cross talk of combined gene and cell therapy in ischemic heart disease: role of exosomal microRNA transfer. Circulation 130:S60-S69. doi:10.1161/CIRCULATIO NAHA.113.007917

61. Scirica BM, Bhatt DL, Braunwald E, Steg PG, Davidson J, Hirshberg B, Ohman P, Frederich R, Wiviott SD, Hoffman EB, Cavender MA, Udell JA, Desai NR, Mosenzon O, McGuire DK, Ray KK, Leiter LA, Raz I (2013) Saxagliptin and cardiovascular outcomes in patients with type 2 diabetes mellitus. N Engl J Med 369:1317-1326. doi:10.1056/NEJMoa1307684

62. White WB, Cannon CP, Heller SR, Nissen SE, Bergenstal RM, Bakris GL, Perez AT, Fleck PR, Mehta CR, Kupfer S, Wilson C, Cushman WC, Zannad F (2013) Alogliptin after Acute coronary syndrome in patients with type 2 diabetes. $\mathrm{N}$ Engl J Med 369:1327-1335. doi:10.1056/NEJMoa1305889 